WRITING AND SPEAKING: DIFFERENT VERSIONS OF LANGUAGE

\section{Dick Lazenby}

In recent years, people seem to have realized the necessity of communicating with all of the people of Canada, which obviously means using both official languages. I grew up attending school in British Columbia and worked for some years before I had a chance to live abroad (abroad includes Montreal and Toronto). With the benefit of several polyglot years working in different parts of Europe, and further schooling, I found it possible to earn a living as a freelance writer and technician in British Columbia. This article is intended to offer some practical comments on the business of writing scripts for Information pictures and training films.

\section{PRINTED SPACE VERSUS ORAL SPACE}

Technical writers all know that we are living in the Space Age. Oh --I don't mean Outer Space, with all its hardware, or Inner Space with all its psychology: Writing Space, I mean, which is measured in column inches (unless the Metric Commission abolished the phrase?) --a given area to cover, a given time slot to fill. For print, there are two questions: how much can we say; and, how well can we say $1 t$ ? Writing for radio or training films, one faces the additional question of how to pronounce the words. Solving our writing problems means answering these three questions in a manner acceptable to ourselves and our cllent (editor, employer). The basic data is generally supplled to us, and we construct the messages in our own language. This is difficult enough. But what if our client decides that the readership is too limited in one language, and the message must also reach readers and 1 isteners in other languages? A translation is required.

My first intimation that there were two officlal languages in Canada was provided by the cornflakes box. At home we ate porridge purchased In a sack; at grandmother's we had cornflakes out of a box which was printed in two languages. The English we could understand, but the
French was a foreign language; Grandmother said it was the other language of Canada. Oh, like Italian or German or Japanese or Spanish which the other kids in school could speak? No, no--French is an officlal language. We amused ourselves by reading words out loud,-incorrectly of course, since we used the vowel quantities and pronunciation of English speakers. Grandmother paid no attention; she had no French. At high school, where most students found it difficult enough to pass English, both Lat in and French were taught as dead languages, useful for reading, but with no particular value placed upon correct pronunciation. This was British Columbla, where very few people were able to speak French at home, where radios still required a licence, and where television would not arrive for two decades.

The cornflakes box provided an excellent model of the space problems encountered in providing two versions of the text. The French version, with more syllables and more words, took up more space than the English version. to say the same thing. This problem was handled in several ways. Sometimes smaller type was used to make the French match the English space. Sometimes there was more white space between paragraphs in English. Sometimes a part of the English text was not reproduced in the French verston. Working years later with instructional films and radio broadcasts, I found a very similar situation for translations from English into French, and also into German, or Japanese, or Spanish: printed or spoken, messages in other languages seem to require about 20 percent more space or time than the English version. Simple enough to deal with, one would think; just allow more space. But 20 percent more space means 20 percent more time as wel1; and what is white space in the English printed text, becomes silence in the spoken version, causing "dead air" in radio or a "gap" in a film narration. The eye has been trained to accept space; the ear has not.

Speaking a language is so natural to us, that we normally fail to appreciate the difficulties of writing for speakers. By the time we are five years of age, most of us are 1 inguistic "adults" who have mastered the significant phonemic oppositions of our native tongue, and can make all of the different sounds required. We have also mastered the fundamental rules of usage,--the grammar of our language. 
All this has been done before we begin reading. Perhaps this is why most of us never do seem to make the connection between spoken words and written words. Why else should professional speakers make the silly mistakes which are heard every day, in the pronunclation of words. It is not merely the sports announcers who have difficulty with the names of people and places from another country; news announcers and professors have a similar difficulty. It derives from the fact that they are reading from a written or printed text.

\section{WRITTEN ERRORS VERSUS ORAL ERRORS}

Virtually everything which is spoken in instructional films or slideshows, is read from a script. If we are following the script with our eyes, we may fall to hear the error we do not see. This happens because our mind is checking to see whether the spoken words match the printed text, and not thinking about whether what is being said makes any sense. Many times at the studio $I$ have caught mistakes because I did not have a script in front of me when the announcer was rehearsing. This is perhaps similar to proof-reading your own material; a fresh eye will see what you may fail to detect. It took me some years to learn, that it was necessary to read aloud every cue at home, and make corrections at the typewriter, after reading aloud. It is necessary also to inform oneself about pronunclations--another problem which does not occur in print. Technical jargon, scientific names, place names in another Province, street names--any of these can become a problem when mis-pronounced. It is expensive to stop in the middle of a recording session when a doubt arises. Better to read scripts aloud at home, use a dictionary, consult a 11brary, check and doublecheck with your technical advisor. In recent years I have found it useful to raise the question of pronunciations during my early technical brlefing sessions, so that if the advisor is not certain, there is time to find out. I write phonetic pronunciations into the script [in square brackets] so that the client may approve them and the narrators may be guided by them. I also make liberal use of commas, semi-colons, dashes, colons, all to indicate the pauses and hesitations of spoken language. Printers have removed most of these little pausemarks as unnecessary in books; but they are most necessary for guidance In reading aloud.
Timing of cues is also essential for f $11 \mathrm{~m}$ work, because the narration is being fitted to the picture footage. If the technique being demonstrated runs through in 35 seconds, that may be all the time you have. If a key action takes place, say, at the 16-second mark, you may have to place key words so that they are spoken exactly at the scene change. This may involve inverting the normal sentence order, in such a way that the viewer will still understand what is belng sald. Since the viewer is watching the film, it is possible to accept inverted order without question so long as it appears to $\mathrm{fit}$ the footage. I time all my cues with a stopwatch, allowing for entry time into the sequence, and for planned pauses in narration while the viewer is absorbing the significance of the $f 1 \mathrm{~m}$ footage. Particularly in training films, there must be time for the viewer to absorb what is being shown and being said. (This may be analagous to "white space" in print.)

\section{ACCURATE VERSUS INACCURATE INFORMATION}

An important problem which is not normally discussed, is the rellability of one's informants. Clients do not care to be cross-questioned about their own account of their own business. Nevertheless, the writer is responsible to provide an accurate script, and if the piece goes out with an error in it, the writer gets the blame. In writing accounts of an actual process or procedure, I arrange when possible to visit the place of operations, and discuss what actually happens with the foreman, the head chemist, or whichever appropriate person. Always, my scripts show the benefits of such a visit. It is possible then to make corrections to the draft script. I have had clients question my accuracy often enough, and have learned to deflect these doubts by offering evidence from the people who are doing the work. In the long run, the client appreciates this.

Frequently, the client wishes to make mention of important facts for which there is no supporting footage. Naturally, such cues must be provided early enough for the film editor to add some sort of footage to lengthen sequences and provide the necessary time; and you may have to explain these techniques to the client. With practice, one learns to insert quite an appreciable amount of information into a film this way, without destroying the continulty of the story, or distracting the viewer. Clients also like to meddle with scripts. More than 
once, I have had technical advisors sit down and convert my scripts into magazine or perfodical articles, adding reams of information, changing the sentences, cutting out material and replacing it;--all of this, of course, at their desk, with no reference whatever to the film footage. One thanks them politely, puts their work aside, and continues to write a script which serves and supports the film.

\section{TRANSLATION VERSUS TRANSLITERATION}

Finally, the film is completed, and it does its job. The client likes it, and decides to have a version made in another language or languages. This means getting a translation. You have filled up all the space with wall-to-wall commentary in the English version, and it is going to take longer to say the same thing in other languages;--but the picture is cut, and therefore fixed at that length, so there will be a problem with the other language version. Clients are normally 1gnorant about other languages, and generally the cllents do not bother to see the versions, and cannot know what sort of an impression they will make upon viewers in another culture. This puts more stress upon the writer, who must take some responsibility for securing a respectable product. The people doing technical production on the film seem unaware of the problem, or unwlling to see $1 t$. Who is going to tell them? Nobody listens to writers.

I once worked on a series of versions of information films which were produced originally in English by English-speaking editors. The people hired to do the versioning were translators but not fllm writers; they translated every word from English into the new version language. Of course it took too long to speak the cues normally; the narrators were goaded into speaking as quickly as possible, rushing through their texts, and generally destroying the mood of the films. However, the original producers did not appear to understand the difference and the work was sent out in that condition. It was worse than useless. Many times I have listened to French-speaking announcers hurrying through the text they are provided with, to make a version which matches the English. Of course they know how bad it 1s,--but they want to continue working.
Versioning can be as challenging as writing an original script, perhaps more so. Technical topics use spectfic references, in plain language, perhaps with scientific names which mean the same thing in every language. The more the original script deals with nuts-and-bolts writing, the closer may be the translation. lacts are facts, and machine parts are machine parts. There is still a struggle with the pressure of space and time, if the new language takes longer to say it. Where the English original employed sentence inversion to allow a key word to fall exactly over a key scene, the version language is sometimes taxed, and the translator may only be able to provide a mediocre cue. The real trick is in finding words to leave out. If the English version has left spaces, and permitted some gaps in the flow of narration, it may be possible to offer an almost-complete version in the new language.

Such success is ordinarily only possible with basic language and basic concepts. Much of the bad work which is sold as translation, I would denominate as transilteration, the word-for-word rendering into the second language. But this kind of hack work cannot supply adequate translation of more poetic and Imaginative writings, which demand equally senstive and Imaginative expression in the tongue of another culture. And so we end as we began; I have run out of space.

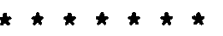

With a Bachelor of Commerce in advertising and business administration and a Master's degree in English 1anguage and literature, both from U.B.C, plus a doctorate in the history of Ideas from the University of Sussex, Dick Lazenby works as a [ree-lance technical writer and researcher in Vancouver, under contracts with federal and provincial government agencies and large and small manufacturers and distributors, to provide background articles, process tratning programs, public information articles and films, etc. 